\title{
Disquisición sobre el misterio absoluto
}

\section{JUAN LUIS SEGUNDO, Montevideo, Uruguay.}

Un joven teólogo mexicano, Javier Jiménez Limón, ha hecho una excelente recensión,! la mejor que conozco, de mi obra El hombre de hoy ante Jesus de Nazaret. ${ }^{2}$ Creo que, al llamarla excelente puedo ser objetivo y hacer abstracción de algunos juicios elogiosos que alli hace: la extraordinaria calidad que le reconozco es haber condensado con notable penetración y claridad las grandes ideas de una obra farragosa que me gustaria reescribir en forma más ordenada y clara.

Al terminar la recensión, Jiménez Limón señala "tres aspectos a discutir," formulando ciertas criticas negativas o, por lo menos, interrogativas. A una de ellas, que se refiere a juicios concretos que en mi obra se hacen sobre otros teólogos latinoamericanos, ya tuve ocasión de explicarme en una respuesta a Hugo Assmann en la revista teológica brasileña Perpectiva teológica (Belo Horizonte, 1983, 15, 385-400) bajo el título "Notas sobre ironias e tristezas." Otra de esas críticas versa sobre el uso de la clave política para la exégesis histórica de los sinópticos. Creo que la crítica se funda aqui en el malentendido de que yo elegi esa clave. Lo único que puede discutirse, a mi modo de ver, es si, sí o no, el Jesús histórico la eligió para comunicar su mensaje profético sobre el reino. O si eligió otra. Porque si la clave, por limitada, constituye un inconveniente para comprender su mensaje, éste no proviene de alguien que pueda ser llamado "verdadero hombre."

Pero la tercera merece, creo yo, un amistoso diálogo. Una búsqueda que puede contribuir a esclarecer uno de los puntos más decisivos de la obra. Hela aqui: “ ¿Un sentido deficitario del misterio absoluto? Esta es la crítica más hipotética intuitiva. Simplemente anotamos la sospecha de que su ejemplar cuerpo a cuerpo con el pensamiento positivista, y su más que justificada crítica al religiosismo, le han impedido a Segundo reencontrar y expresar con vigor la apertura al misterio absoluto. Está presente, sin duda, por su insistencia en los datos trascendentes, por la importancia que da a la escatologia en el sentido más fuerte de la palabra, por su interpretación de Calcedonia. Simplemente 
quisiéramos mostrar aqui nuestra esperanza de que Juan Luis Segundo muestre en su trabajo teológico posterior lo que aqui ha quedado, quizás justificadamente, en sordina. " Pues a eso vamos...

Jiménez Limón tiene, en su critica, la delicadeza de dejar claro que el tratar este tema, dentro del contexto al que quiere hacer justicia el libro, es un asunto de oportunidad. Más aún, que esta oportunidad no versa tanto sobre si tratar o no tratar del misterio, pues de él se trata en varias partes y de varias maneras, sino en tratar más todavía de él. Con juicio certero percibe que ello no podría hacerse sino ampliando y aclarando lo que en el libro se dice sobre el Concilio de Calcedonia, o sca sobre la manera con que Jesús de Nazaret, perfecto hombre y perfecto Dios, nos revela ese misterio $(\mathrm{Jn} .1,18)$.

Yo siento en mi el peligro que sentía Chesterton: una buena pregunta que se me haga puede provocar un libro... Espero que ello no ocurra aqui, pero mi tarea no puede ser otra que volver a retomar el capilulo consagrado en el tomo II/2 a ese mismo tema (capitulo I, “Jesús y Dios: aproximación al Concilio de Calcedonia"), tratando de formular su contenido de una manera más clara y sucinta, para luego pasar a disculir la relevancia que ello tiene para el tema puesto sobre el tapete: la apertura al misterio absoluto, o sea, al misterio de Dios.

¿Por qué volver al siglo $\mathrm{V}$ en nuestra búsqueda? En la obra de marras, se respondia a esta pregunta que a ello nos llevaba la sospecha de que el Concilio de Calcedonia, donde se habia trataclo de la manera correcta de hablar sobre la divinidad de Jesucristo, más que estar pasado de moda no había sido aún comprendido y aplicado lo bastante. Aquí, amén de esa razón de fondo, tenemos una más directa todavía. El Vaticano II se refiere a un doble misterio revelado en Jesús: el misterio del Padre y el misterio del hombre. "Cristo... en la misma revelación del misterio del Padre y de su amor, manifiesia plenamente el hombre al propio hombre... Este es el gran misterio del hombre que la revelación cristiana esclarece (illucescit) a los fieles" (GS 22; el subrayado es mio). Aquí se nos plantea el caso de un misterio que "quedaria" absoluto en (o a pesar de) una revelación que "lodo lo ilumina con nueva luz" (GS 11). Y esta antinomia es, precisamente, to que justifica la búsqueda que sigue.

Esta búsqueda exige unas breves observaciones previas. La primera es que vamos a suponer, como hipótesis heuristica, que desde el Concilio de Nicea hasta el de Calcedonia se recorre un cierto camino dogmático dominado por un problema central: no tanto el de (el dato de) la divinidad de Jesús cuanto, como ya se dijo, el de cómo concebirla y expresarla correctamente. En otras palabras, admitido el hecho de que Jesús pertenecia a la divinidad, cómo se debia concebir y expresar ésta de tal manera que quedara al mismo tiempo intacta su humanidad. Si insisto en la palabra "expresar" es porque creo percibir que, casi diría, lo más importante de la problemática está generado por una crisis linguística. Desde Nicea a Calcedonia no se discutió nunca ni la divinidad 
ni la humanidad de Jesús. Pero cada vez se percibió con más claridad que era dificil "hablar" un lenguaje que hiciera justicia a ambos.

La segunda observación es, pues, que, de acuerdo a lo que precede, la - pequeña- búsqueda que aqui se emprende, prescinde, por un derecho heurístico y por su cuenta y riesgo, de los datos anteriores acerca de cómo el mismo Nuevo Testamento llega a la certezad de que Jesús es, si no "el Dios," sí "Dios." En olras palabras, comienza su planteamiento con el concilio de Nicea. Y lo termina con el de Calcedonia. Aun sabiendo que otros datos sobre la doble naturaleza de Jesús ocuparon a concilios posteriores. Nos parece que, después de Calcedonia, el problema que nos ocupa, el "linguistico," queda resuclıo. Bien o mal, pero resuelto. Y no se vuelve a plantear durante siglos.

La tercera observación es que lomamos como campo de nuestra búsqueda y como hitos en el tratamiento de nuestro problema tres concilios ecuménicos: el de Nicea, el de Eleso y el de Calcedonia. No ignoramos que detrás de los acontecimientos conciliares hay un inmenso campo de investigación consıiluido por los datos de la patristica y aun de la historia eclesiástica. Nuestra apuesta heurística es que los resultados de esos tres concilios (no nos parece que el segundo concilio ecuménico, el de Constantinopla l, haya aportado naida decisivo en la materia) constituyen el desarrollo necesario y suficiente del problema. Suficiente, claro esıà, para explicar lo que luego ocurre durante siglos, en esta temática. Y una cosa más. No se nos oculta que esa historia que dejamos de lado en nuestra investigación puede, en principio, invalidar nuestras conclusiones. Se puede, en efecto, arguiir que luchas entre personalidades, como la de Cirilo contra Nestorio o contra Eutiques, hayan determinado ciertos concilios de tal manera que parezca una ingenuidad el considerarlo como hitos del desarrollo de un problema. Esto puede, obviamente, ser objeto de discusión. Mi hipótesis, sin embargo, es que, cualquiera que haya sido la virulencia de esas controversias puntuales y su influencia a corto plazo, el resultado, al nivel de una "meta-historia" del dogma, equivale a la del planteamiento y solución del problema antes aludido: cómo hablar coherentemente de la divinidad y de la humanidad de Jesús.

Trataremos pues, en una primera instancia, de reconocer los rastros de ese desarrollo en los tres concilios mencionados. Luego intentaremos traducir ese mismo desarrollo en términos del problema linguístico implícito (aunque a veces también explícito) en él. Y finalmente, y en base a los resultados de esa búsqueda, nos plantearemos el problema que origina este articulo: cómo y dónde queda el "misterio absoluto" de Dios después de su revelación en Jesucristo.

\section{II}

1. Lo esencial sobre cristologia en el concilio de Nicea (325), ha quedado expresado en esa formula de fe o credo que, como todos saben, aún hoy se recita en la liturgia cristiana en el comúnmente llamado "credo largo." Como es igualmente sabido, el concilio formula, en términos positivos, una condenación del arrianismo que concebia la divinidad del Hijo de Dios como una divinidad inferior, creada, subordinada a la del Padre. Desde el punto de vista del 
lenguaje digital, salta a la visıa como decisiva una palabra: "consubstancial." El resto lo constituyen expresiones icónicas, como "engendrado, no creado" o "Dios de Dios, luz de luz," eic.

Se diria que, aparte de solucionar este problema de la supuesta inferioridad "substancial" del Verbo, Nicea no hace sino repetir fórmulas linguisticas, más o menos ingenuas, usadas desde los tiempos del Nuevo Testamento, para expresar que el Jesús del siglo I de nuesira era, era a la vez hombre y Dios.

Pero, como la palabra "consubstancial" indica una intención de superar esa "inocencia," los términos en que se expresa Nicea están ya preñados de un problema que llevará, el siglo siguiente, a Efeso y Calcedonia. Para recibir este planteamiento implicito, conviene leer de una vez. la parte central de ese credo consagrado a Jesucristo: "Creemos... y en un solo Señor nuestro, Jesucristo, Hijo de Dios, nacido unigénito del Padre, esto es de la substancia del Padre, Dios de Dios, luz de luz, Dios verdadero de Dios verdadero, nacido, no hecho, de una sola substancia con el Padre, por quien han sido hechas Iodas las cosas, las que hay en el cielo y en la tierra, que bajó por nuestra salvación, se encarnó y se hizo hombre, padeció y resuciló al tercer dia, subió a los cielos y ha de venir..." (Denz.54).

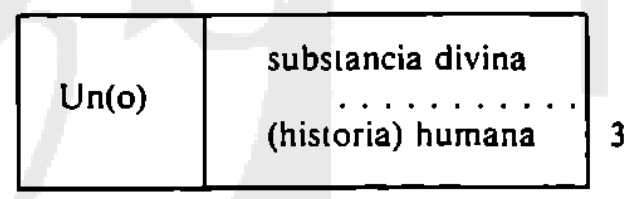

En el cuadro adjunto ( $y$ en los siguientes correspondientes a Efeso y Calcedonia) trato de hacer visible algunas características linguísticas que me interesa señalar a la atención del lector después de examinar las expresiones usadas por el concilio. Veámoslas en este caso.

Lo primero que llama la atención es lo que directamente - in rectoquiere definir el Concilio de Nicea: que la divinidad que le pertenece a Jesús, por estar éste identificado con el Verbo o el Hijo unigénito de Dios, es "substancialmente" igual a la del Padre. O sea, en nada inferior, cualquiera que fuese la razón - creación o encarnación - para una pretendida inferioridad con respecto a la del Padre, o sea, "el Dios."

Pero, y en segundo lugar, una cosa que tal vez llama menos la atención, pero es el comienzo del planteamiento linguistico, hay en la construcción de la frase un hecho relevante: el complemento del verbo "creemos en," el que luego se convierte en sujeto de todo lo que sigue, es "uno." Ese uno es, por supuesto, Jesucristo. ¿Por qué se habla de "uno," cuando inmediatamente se lo nombra? A primera vista alguien podría pensar que esţe "uno" no es más que la repetición obligada de otro "uno" al comienzo del credo, cuando se dice que "Creemos en un solo Dios Padre." Pero no es así. En esta primera ocasión (y aunque no nos sea dado saber con qué puntuación se pronunciaría la frase), el "un solo Dios" es una obvia afirmación de monotésmo. Nosorros 
ponemos hoy -así lo hace, con razón, la versión española del Denzingeruna coma entre Dios y Padre: "creemos en un solo Dios, Padre..." El uno, aplicado al Padre, se refiere a la "unicidad" de Dios. Pero no tendría sentido el afirmar tal "unicidad" en el caso del Hijo. Y de hecho observamos que no se habla de "un" Espiritu Santo. El "uno" que precede al término Jesucristo no puede referirse a su "unicidad." Se refiere al problema específico que presenta Jesucristo: su "unidad." O sea, en términos linguisticos, al fenómeno único de que, en la fórmula que analizamos, ese sujeto "uno" recibe, sin solución de continuidad, predicados divinos (consubstancial, Dios de Dios, engendrado por el Padre, causa creadora del universo...) y predicados humanos (se hizo hombre, padeció y resucitó...).

En tercero y último lugar, entre esas dos listas de predicados que se suceden en relación con un sólo sujeto hay una diferencia destinada a cobrar, en lo sucesivo, una importancia cada vez mayor. No se trata de lo divino y de lo humano, considerados en sí mismos. Se trata de lo que podríamos llamar, con un término más usado en exégesis bíblica, el "género literario" propio de cada uno de esos planos. La "substancia divina" se expresa en términos que, si no pueden ser eternos - porque no los contiene tales el lenguaje del hombre-si pretenden ser intemporales. Aluden, genéricamente hablando, a una naturaleza o substancia abstracta. Por el contrario, los predicados humanos (aun pudiendo referirse a la naturaleza abstracta del ser hombre) son, en la formula, predicados históricos acerca de la vida, muerte y resurrección de Jesús. Asi, en forma sucesiva, substancia divina e historia humana convergen en "uno," Jesucristo.

2. El Concilio de Efeso, a pesar de todos los pesares y de la dificultad de saber a qué se le puede llamar tal, tiene una importancia determinante para el problema que aqui se plantea. Y esa importancia está en que, más que Nicea y Calcedonia, los "Anatematismos o capitulos de Cirilo," afiadidos a los cánones, advierten que el problema de teología que había que resolver acerca de Jesucristo era originalmente linguístico. Dicho en otras palabras, su punto de partida en el planteamiento del problema consistia explícitamente en una dificultad de lenguaje.

Ello aparece con mucha claridad en los tres anatemas claves, que aqui citamos en su orden lógico: "Si alguno distribuye entre dos personas o hipóstasis las voces ( $=$ expresiones) contenidas en los escritos apostólicos o evangélicos o dichas sobre Cristo por los santos o por El mismo sobre si mismo; y unas las acomoda al hombre propiamente entendido aparte del Verbo de Dios, y otras, como dignas de Dios, al solo Verbo de Dios Padre, sea anatema" (canon 4; Denz. 116).

De este principio derivan otros dos cánones que presentan ejemplos: " $\mathrm{Si}$ alguno no confiesa que el Verbo de Dios padeció en la carne y fue crucificado en la carne, y gustó de la muerte en la carne... sea anatema" (canon 12; Denz. 124).

Como se ve, estamos de lleno en las inesperadas consecuencias linguísticas de aquella al parecer inocente "unidad" en la que convergían una substancia 
divina y una historia humana. Esa convergencia no parece "compatible" o condigna con realidades tan opuestas como lo divino y lo humano. Lo que conviene a uno no conviene a otro. Lo humano no se puede "dignamente" predicar de Dios. Por ello, compatibilizar el lenguaje supone distinguir, en Jesús, los sujetos. Esta parece ser la única consecuencia lógica. Pero veamos lo que el concilio (o, por lo menos, Cirilo) hace aceptar.

\begin{tabular}{|c|c|c|}
\hline $\begin{array}{l}\text { (Uno) no dos } \\
\text { personas o } \\
\text { hipóstasis }\end{array}$ & $\begin{array}{l}\text { (predicados) divinos } \\
+-+-+-+-+-+-+ \\
\text { (hisıoria) humana }\end{array}$ & $\mid \begin{array}{c}\text { (comunicación } \\
\text { de } \\
\text { lenguajes) }\end{array}$ \\
\hline
\end{tabular}

En primer lugar, "Dios es según verdad el Enmanuel." Lo que, Iraducido, quiere decir que el "Dios con nosotros" es una realidad tal que debe inventarse su propio lenguaje, un lenguaje "digno" de la encarnación. Así, debe prohibirse el uso de "voces" o expresiones que, por salvar la divinidad de manchas demasiado humanas, separen los predicados que parezcan propios respectivamente del hombre y de Dios. Se insiste, al mismo tiempo que se clarifica aquel "uno" de Nicea, en la unidad de sujeto para tcdas las cosas, divinas o humanas, que se prediquen de Jesucristo.

En segundo lugar, cabe explicar el que hablemos de unidad de "sujeto." La palabra no está, tal cual, en Efeso. Efeso prohíbe, en este caso específico y único, referir las expresiones a "dos personas o hipóstasis." Lo que obviamente equivale a decir que se trata de una persona o sea de una hipóstasis. Usar cualquiera de estas dos palabras no seria laltar a la verdad. Pero "persona" era un tèrmino en aquel tiempo aún demasiado joven como para cargar todo el hondo sentido que hoy vehicula. No existia en el lenguaje de aquella época un término con la riqueza semántica de nuestro actual substantivo "persona." El término asi traducido - prósopon- significaba ante todo la máscara que el actor llevaba en las representaciones teatrales y que servia para facilitar la identificación de su rol por parte del espectador.

Por lo que hace a hypóstasis, es sabido que su ambiguledad se percibe aún en su equivalente moderno: "substancia." Esta puede significar el ser o la esencia de algo particular, y en este sentido se parece mucho a persona 0 , por lo menos, a sujeto; pero también puede significar el ser absıracto, la naturaleza (substancia genérica) de varias cosas semejantes. Por eso, creo que, para lo que verdaderamente importa en el problema que nos ocupa, la palabra "suje10," con su base etimológica, puede reemplazar con ventajas a "substancia" o hipóstasis. Y aún, por la razón ya dicha, a "persona."

Ese sujero, Verbo de Dios o Jesucristo, es, pues, uno, no dos. Y a ese único sujeto hay que referir igualmente las voces que proceden de los elementos divinos y humanos que de él se predican. Ese es el único lenguaje "digno" de Enmanuel, el único apropiado a la realidad de la encarnación. 
En tercer lugar, sin embargo, Efeso (en medio de un mundo donde la cultura griega es aún dominante) es consciente de que asi se le exige un tour de force al lenguaje. En efecto, si se ha de cumplir la exigencia del cuarto canon, es menester admitir el (remendo realismo (o humanismo) de la encarnación. Ya el prólogo del cuarto evangelio lo había mostrado. El griego tiene dos verbos para expresar la idea de ser, según se trate de un ser eterno y esencial (einai) o de un ser creado y perecedero (ginomai). Tal vez seria mejor traducir, en el primero caso, "ser" (por si mismo), y, en el segundo, "llegar-a-ser" (por virtud de otro). Pues bien, durante todo el prólogo, el Verbo ha estado recibiendo sistemáticamente el verbo ser, mientras las restantes crealuras, Juan el Bautista, los hijos del Espiritu, han recibido, como corresponde, el verbo llegar-a ser. Pero el versículo catorce, el que enuncia la encarnación, crea un portento linguistico: "El Verbo llegó-a-ser carne y puso su carpa entre nosotros." El Verbo no sólo carga con la realidad humana: carga asimismo con el lenguaje propio del hombre y de la creatura.

En cuarlo lugar, se comprende asi que la encarnación establece una comunicación de realidades. Y que esta comunicación de realidades, cuando se ha de expresar, debe volverse igualmente "comunicación de lenguajes" entre Dios y el hombre. Dios vive - algún término hemos de emplear- realidades humanas en Jesús. Vive lo que es tener una madre, lo que es padecer y morir. Quien quiera sustraer, por dignidad, tales miserias a Dios, simplemente no es cristiano. Pero hay una extraña característica en esta comunicación de lenguajes. Pareceria que, en perfecta lógica, deberia ser una avenida con dos manos: la ascendente y la descendente. Sin embargo, algo rompe aqui los ojos: todos los ejemplos presentados por Efeso a la fe cristiana van en un sólo sentido: el ascendente. La "comunicación de lenguajes" iserá entonces una avenida de una sola mano? Yo me animaría a decir que toda la teologia y, sobre todo, el poder liberador de la teologia, están aqui pendientes de un hilo. De la respuesta -un si o un no- a esta pregunta depende todo. Asi Efesio conduce a Calcedonia.

3. Sólo 20 años transcurren entre Eleso (431) y Calcedonia (451). Esto, en apariencia, podria apoyar la tesis de que Calcedonia es una reacción contra Efeso, y no, en rigor de verdad, su continuación o culminación. Nuestra hipótesis, como ya lo indicamos, es la contraria. Cualquiera que haya sido la voluntad explicita de los actores de este drama dogmático, pareceria que una especie de "astucia de la razón," si no sin ellos, pero si sobre ellos, conduce el problema a su desenlace lógico.

La pregunta fundamental es, en ese caso: ¿qué habia quedado pendiente en Efeso? Ya se indicó que salta a la vista alli un cierto desequilibrio. Si la unión implicada por un sólo sujeto o persona fundamenta una comunicación de lenguajes (como luego se llamó a este fenómeno, haciendo honor a su origen linguistico), ¿por qué sólo se dan ejemplos siguiendo la via ascendente? En otras palabras, ¿por qué se ha de decir que Dios tuvo madre, padeció y murió, y no se dice, a la inversa, que el hombre que es Jesús es inmutable, inaccesible, inmortal, omnisciente y todopoderoso? 
Detrás de esta pregunta apunta un problema más profundo. Si lo que se sabe de la historia humana de Jesús ha de introducirse (por vía de la comunicación en el lenguaje) en el concepto de Dios, pareceria que, de igual manera, los atributos divinos tendrían que caber en el concepto de lo que es ese hombre Jesús tal como vivió su historia. Pero -y este "pero" es formidable - si atributos divinos como los mencionados en la frase anterior se predican de Jesús, resulta que toda la historia de Jesús percibida por los testigos de su vida es falsa. Son falsos sus cambios, falsas las relaciones que tuvo con otros seres humanos, Calsa su angustia ante el dolor y la muerte y falso su mismo dolor y su misma muerte...

Dicho en otros términos, la "condición" o "naturaleza" humana, tal como surge de nuestra experiencia, es contradictoria con esos atributos. Los diferentes predicados que implicaria esa comunicación de lenguajes (descenden(e) no revelarian a Dios porque, si se los quiere mezclar con los predicados que surgen de lo que para nosotros es necesariamente un hombre, deshacen a Jesús y lo convierten en un fantasma, en alguien que simplemente "jugb a ser hombre" sin serlo en realidad. Porque resulta que el concepto hombre ya esıá lleno de contenidos concretos.

Pero, ¿por qué no ocurre otro tanto con la via ascendente? ¿Cómo es que se pueden introducir en el concepto de la "condición" o "naturaleza" divina predicados procedentes de una historia humana, cabalmente humana - como tener madre, padecer y morir - sin destruir ese mismo concepto? Si el concepto de hombre se resistía a la "comunicación" linguística por estar ya lleno, el concepto de Dios, que la acepta (según Efeso), ¿estará entonces vacfo? ¿Habrá asi que tomar en serio metafísicamente la loca metáfora paulina del "vaciamiento" (kenosis) de la divinidad en Jesús, según Filipenses 2,7?

Leamos y analicemos los elementos más pertinentes a este respecto de la larga formula calcedonense: "...Todos a una ensefiamos que ha de confesarse a uno sólo y el mismo Hijo, nuestro Seffor Jesucristo, el mismo perfecto en la divinidad y el mismo perfecto en la humanidad, Dios verdaderamente, y el mismo verdaderamente hombre de alma racional y de cuerpo, consubstancial con el Padre en cuanto a la divinidad, y él mismo consubstancial con nosotros en cuanto a la humanidad... en dos naturalezas, sin confusión, sin cambio, sin división, sin separación, en modo alguno borrada la diferencia de naturalezas por causa de la unión, sino conservando más bien, cada naturaleza su propiedad y concurriendo en una sola persona y en una sola hipóstasis, no partido o dividido en dos personas, sino uno sólo y el mismo Hijo Unigenito, Dios Verbo Seffor Jesucristo..." (Denz. 148). En honor a la brevedad omitimos explanaciones, citas biblicas y, lo que tal vez es más importante, algunas alusiones confirmatorias de los "Anatematismos de Cirilo," (como la afirmación de la maternidad "divina" de María).

\begin{tabular}{|c|c|c|c|}
\hline Una & naturaleza divina & Comunicación \\
persona & -...-.-.-.......... & de lenguajes & linea \\
(sujeto) & naturaleza humana & sin confusión & asc.) \\
\hline
\end{tabular}


Conviene notar, en primer lugar, que Calcedonia utiliza por primera vez la fórmula clásica: una persona, dos naturalezas. Por eso, aunque valga aqui también lo dicho de Efeso, acerca de los términos usados para expresar lo que hoy llamamos "persona" (en aquel tiempo, prósopon y/o hypóstasis ) prefiero usar la palabra que se ha vuelto igualmente clásica. Sólo añado "suje10" para indicar que, en aquel entonces, ese término seria tal vez el que más se acercaria a lo que el concilio quiere indicar. En cambio, lo que antes no tenia un nombre especifico, ahora to liene: naturaleza (en griego physis). Antes de Calcedonia, recordará el lector que se atribuian indistintamente a ese único sujeto (Verbo de Dios-Jesucristo) atributos divinos (se hablaba de substancia) y predicados provenientes de su historia humana (como el "hecho" de nacer, padecer, morir, etc.). Aqui lo que es dos se identifica con un substantivo $y$, por desgracia, ese substantivo refleja demasiado la tendencia "cosista" de una filosfia griega que comenzó siendo precisamente una búsqueda de la esencia de las cosas más elementales. No obstante, y a pesar de todos los pesares, el nombrar, bien o mal, lo que es dos servirá para llamar la atención sobre los respectivos conceptos que son el origen del problema linguístico: lo divino y lo humano.

En segundo lugar, se ha dicho, no sin razón, que Efeso representa el acento puesto en la no separación. La comunicación de lenguajes es su punto fuerte, su hallazgo. Calcedonia, por el contrario, pondría el acento, si no en la separación, por lo menos en la distinción. A ello nos referimos en el esquema colocando una linea divisoria (neta) entre naturaleza divina y naturaleza humana. En efecto, el "dos" que se saca del terreno de las personas, se hace explícitamente presente en el campo de las naturalezas. Estas, por más que no estén separadas "personalmente," no están "confundidas" ya que cada naturaleza "conserva lo que es propio" de su concepto y no se puede nunca "borrar su distinción." El que las naturalezas no se mezclen jamás en Jesús será el gran principio epistemológico de la solución que da Calcedonia al problema que plantea Efeso.

En tercer lugar, en efecto, Calcedonia, al negar toda mezcla o confusión, cierra una puerta importante al concepto de lo divino: la experiencia. ¿Por qué pretendemos tal cosa? Muy simplemente: si las naturalezas nunca se mezclaron, lo que la experiencia percibió en Jesús fue solo lo humano. Esta conclusión, aparentemente tan simple, no fue sacada. La idea que, aún hoy, se tiene de Jesús no es tento la que surge de Calcedonia, sino la que Calcedonia condena: la de un semidiós. Pensamos que en Jesús, el conocimiento humano se mezcla con el conocimiento divino (lo que hace que Jesús se entregara a la muerte sabiendo que sólo estaria un día y medio en el sepulcro...). Imaginamos, si es que realmente podemos hacerlo, que el Jesús que suda sangre en el huerto, está al mismo tiempo gozando las delicias celestiales, pleno de la visión de su gloria eterna y del éxito del reino de Dios. Pensamos en un Jesús que está, todo el tiempo, consciente de su divinidad... En una palabra, colocamos en Jesús cosas que no vienen de lo que la experiencia de los testigos percibió en él, sino de lo que procede de nuestro concepto - presupuesto- de lo que debe ser 
un Dios. Practicamos límidamente, pero practicamos al fin, la via descendente de la ya mencionada "comunicación de lenguajes."

Debemos, sin embargo, preguntarnos, en un cuarto punto: ¿cambió en algo el planteamiento del problema linguistico el concilio de Calcedonia? La respuesta ha de ser que sí cambió, puesto que radicalizó sus términos. Hablando de Efeso nos preguntábamos si habría que pensar que el concepto de Dios estaba vacio, para que pudieran entrar en él - sin contradicción absoluta- predicados que proceden de la historia humana de Jesús. Y Calcedonia nos lleva aún más lejos en ese camino. Nos confirına ese "vaciamiento" del concepto de "lo divino," pues nos obliga a decir que lo divino no era perceptible — no era objeto de experiencia - en la vida humana histórica de Jesús. Y ahora sí, cabe preguntarnos: ¿cómo hemos llenado entonces de contenido concreto ese concepto de lo que Calcedonia llama la "naturaleza divina," o sea, el concepto de lo que Dios es por necesidad? ¿De dónde hemos sacado lo que ha de ser una "vida divina?"

\section{III}

Aquí tenemos que hacer un pequeño alto en nuestro análisis de Calcedonia. En efecıo, si hemos de seguir adelante, tenemos que señalar un obstáculo que nos cierra el camino. Y es la terminología usada por el concilio y proveniente, como ya indicamos, de la filosofia "cosista" griega. Tratemos, pues, de ver qué es lo que se quiere decir con "naturaleza divina." Dios, en efecto, no es un ser "físico" (o sea, "natural") como lo es, hasta cierto punto nada más, el hombre. ${ }^{4}$

El orden del ser, o la escala de perfección de los seres, comienza - desde abajo- por un primer peldanto donde los seres se determinan y, por ende, se ordenan y se conocen por la naturaleza que poseen. En otras palabras, por su género y su especie (y en una medida mucho menor, por sus "particularidades," ya que éstas resultan accesorias en el plano del conocimiento y de la utilización). Por ejemplo, poco importante puedo conocer del agua una vez que he conocido por la química su constitución natural.

Algo significativamente diferente ocurre ya al nivel de los seres vivos. $Y$, sobre todo, a medida que ascendemos la escala de la vida y pasamos de los animales llamados "adaptadores" a los "reguladores." La espontaneidad de estos últimos va haciendo que, para cualquier fin práctico en nuestra relación con ellos, podamos confiar muy poco en un conocimiento que se reduzca a tener en cuenta su naturaleza. No sé cómo tratar a un perro si sólo se de él que posee una "naturaleza" canina. La mayor medida en que el animal se determina por su propia espontaneidad vuelve cada vez més relevante, si no la "libertad" de cada perro, si su historia particular como indice de lo que se puede esperar o temer de el.

De los seres humanos dice ya Sartre, con una evidente exageración, que la existencia precede a la esencia. Lo cual, en buen castellano, podria traducirse diciendo que la libertad precede a la naturaleza. Si por precedencia hubiera 
que entender un cierto orden temporal de preeminencia, la expresión seria falsa, porque precisamente en los primeros años de su existencia, está el ser humano dominado más por lo que en él hay de "Císico." Pero si por preeminencia entendemos cuál es el elemento que, al final de la vida, habrá sido el que más ha determinado el ser hombre, habrá que confesar que el hombre es en gran medida lo que ha querido ser. Su naturaleza es una especie de marco negativo que señala lo que su opción no puede sobrepasar. Pero nadie que esté en su sano juicio consentiria en unirse en matrimonio con un esposo o esposa por el sólo hecho de conocer su "naturaleza humana." Mucho más necesario es conocer su libertad concreta. Pero la libertad concreta sólo se deja ver, hasta cierto punto, por sus rastros o resulıados hisı́ricos. Sólo conozco verdaderamente a un ser humano cuando conozco su historia. La única "imagen" de una libertad es la historia de sus opciones.

Y asi llegamos a Dios. Aquí sólo la formalidad de su infinirud en el ser puede engrendrar un conocimiento cierto. Pero esta infinitud es la formalidad de una libertad o espontaneidad sin limites. Ello significa que Dios es lo que elige ser. Si "naturaleza" significa los limites que un ser no puede sobrepasar, tendriamos que decir que lo único que la "naturaleza" de Dios me hace saber es que Dios no puede ser limitado en nada que elija ser.

Esto que parece obvio para una filosofia que no es ya la griega, no lo era en el tiempo de Calcedonia. El pensamiento procedente de la filosofia creía poder pasar de la formalidad de la infinitud divina a contenidos "concretos" del concepto de Dios. Un ser infinito - motor inmóvil- no podia moverse ni cambiar porque la razón para hacerlo sólo podia haber sido el carecer de algo. No podia tampoco depender de nada ni de nadie ni, por ende, ser influenciado por la buena o mala suerte de ningún ser limitado. No podia amar como aman los hombres, volviéndose dependientes del ser amado, cargando con sus sufrimientos y alegrias y dando su propio ser por la felicidad del otro. Toda esta cadena de deducciones falsamente tautológicas, brotaba de un supuesto conocimiento positivo de la "naturaleza divina." Ello parecía indicar que el concepto de naturaleza divina estaba tan lleno como el concepto de naturaleza humana. Pero todo este edificio con que se pensaba atrapar a Dios estaba cimentado en la significativa ausencia, en el concepto griego de Dios, de la infinita libertad divina. Y esta es la ambigüedad de Calcedonia: usa el término griego de "naturaleza" para referirse al concepto de Dios, pero, obviamente, todo indica que está pensando en el Dios de la Biblia, en el Dios hecho hombre, y en la preeminencia, aquí si absoluta, de la existencia sobre la esencia, de la libertad sobre la naturaleza.

Ahora bien, y esto es lo más decisivo, si Dios es liberlad absoluta ejercida sobre la realidad total, ¿cómo darle un contenido "material," es decir, concreto, al concepto, digamos, de "naturaleza divina?" Si lo dicho antes es cierto, el único camino para conocer la opción de esa libertad infinita será, otra vez, la "historia" de Dios. Y ésta, y no otra, es la visión sistemática que tiene de este camino cognoscitivo hacia Dios la Biblia. Así es cómo se dio a conocer el Dios de los hebreos: como un Dios de la historia, no un Dios de la naturaleza. Sólo que en el Antiguo Testamento esa historia divina se percibe a través de 
mediadores hislóricos que no son Dios mismo, aunque si "imágenes" suyas. En el caso de Jesús, es la historia misma de una persona divina la que nos permite llenar de historia concreta ese concepto de Dios. Es la forma plenamente significativa para nosotros, plenamente humana, con que Jesús vive su historia la que,despojada - formalmente- de sus limitaciones (en una realidad, creada) nos permite saber cómo es Dios.

He aqui por qué la comunicación de lenguajes tiene sólo un sentido ascendente, abierto por el amor descendente de un Dios hecho hombre y revelado en su cabal realidad humana. Una filosofia que investiga naturalezas, sólo puede inventar un Dios a semejanza de una cosa perfecta y/o, negalivamente, hablar de un "misterio absoluto." Pero del Dios de la Biblia, y más aún del Dios cuyo concepto se nos revela a través de la historia plenamente humana de Jesús, se puede y se debe decir lo que ya el Deuteronomio escribia (a propósito del Dios que se revelaba en la ley de Moisés): “...los pueblos que, cuando tengan noticia de todos estos preceptos, dirán 'Cierto que esta gran nación es un pueblo sabio e inteligente. $Y$, en efecto, ¿hay alguna nación tan grande que tenga los dioses tan cerca como lo está Yahvé nuestro Dios siempre que lo invocamos? Y ¿cuál es la gran nación cuyos preceplos y normas sean ran justos como toda esta ley que hoy les doy?"' (DI. 4,7$).^{5}$

\section{IV}

Se podria a partir de lo dicho hasta aqui en busca de nuevas conclusiones teológicas resultantes de lo que se lleva dicho acerca de la fórmula de Calcedonia. Especialmente en lo que se refiere al tema especifico que, desde el comienzo de este articulo, nos propusimos tratar: el del "misterio absoluto" que constituiría, para nosotros, la divinidad.

Pero entiendo que en ese desarrollo faltaria un eslabón, o, por lo menos, ese eslabón sería muy débil si no intentamos dar, lo más brevemente posible, una versión, inteligible para el hombre moderno, de esa "comunicación de lenguajes" que ha sido establecida, pero tal vez no suficientemente explicada.

Si acepıamos por la le la divinidad de ese hombre histórico, Jesús de Nazaret, estamos abocados - aun después de comprender lo que quiere decir Calcedonia - a un problema bastante concreto de lenguaje. O, si se prefiere, más en concreto aún, a dos problemas o cuestiones. Estamos, en efecto, frente a dos afirmaciones que Calcedonia nos lleva a aceptar como cabalmente verdaderas (aunque la verdad, Irente a la falsedad, no tenga grados, con ese "cabalmente" queremos subrayar que las dos afirmaciones son verdaderas en su totalidad, y no sólo parcialmente): Jesús es hombre y Jesús es Dios.

Las dos preguntas o cuestiones a las que nos referimos no tienen nada de extraño y se podrían - y en muchos más casos similares y corrientes, se deberian- hacer: 1) en la afirmación de que "Jesús (S) es Dios (P)" ¿cuál de los dos términos agrega información al otro? y 2) dadas las dos frases "Jesús es hombre" y "Jesús es Dios," ¿están esas dos afirmaciones en el mismo nivel lógico? 
1. Cuando usamos la afirmación (que todo el cristianismo aceptó desde el comienzo, salvo los docelas) de que "Jesús es hombre," nadie piensa en preguntar cuál de los dos términos unidos por el verbo-cópula o verbo-igualdad, o sea, "ser," arroja luz (cognoscitiva) sobre el otro. Una frase como la del ejemplo supone normalmente que los dos términos son conocidos. Y también normalmente, el sujeto designa un objeto más particular y el predicado una categoría más genérica. Si éste es uno de esos casos, parecería evidente que, al señalar la categoría dentro de la cual se ubica Jesús, estamos, con el predicado ( $y$ el verbo "ser"), aportando un nuevo conocimiento al que ya teniamos sobre Jesús.

No obstante, ello no siempre ocurre así. Hay dos campos muy importantes del conocer donde el proceso sigue la dirección opuesta (sin que debamos cambiar el orden que ocupan en la (rase $S$ y $P$, sujeto y predicado). Uno de esos campos es el de nuestro aprendizaje infantil de las categorías. Por ejemplo, si no sabemos aún que significa la categoría "perro," o sea, qué animales específicos contiene, lo vamos aprendiendo de los mayores por la atribución de la categoría a animales particulares que ya conocemos. Y por la consiguiente negación de la categoria para otros animales. Así, un niño y un hombre maduro leen exactamente en dirección opuesta la frase "Fido es un perro." Para el hombre mayor, esta es una información sobre Fido (S); para un niñito que comienza a conocer el mundo, es una información sobre qué es un perro (P). Asi, cuando esta frase se repite con muchos otros sujetos y si, además, se usa la negación en frases como "María no es un perro" o "Polly es una vaca (un no-perro)," el niño va registrando igualdades (entre perros) y desigualdades (entre perros y personas o entre perros y vacas), y va dándole contenido a la categoria o concepto universal de "perro." En otras palabras, por multiplicación, S arroja luz sobre P. Y llena a éste de contenido.

Algo muy semejante ocurre con descubrimientos científicos. La primera vez que la frase "agua es $\mathrm{H}_{2} \mathrm{O}$ " se pronunció científicamente, el término desconocido (en forma parcial) hasta entonces era el predicado $\mathrm{H}_{2} \mathrm{O}$. El agua, en cambio había sido ya objeto de millones de experiencias. Comparando esas experiencias, contenidas en el sujeto de la frase, se encontró, por análisis quimico, una igualdad tal que se generalizó para toda "agua." Lo cual, desde entonces, y sólo desde entonces, permitió sacar del concepto otras cosas que sólo "parecían" agua. Y que, hasta entonces habia tenido "derecho" semántico a llamarse agua. Asi, de alguna manera, la ciencia repite, en forma más sistemática, la experiencia infantil de la formación de categorías.

Cabe, pues, en buena lógica, preguntarse por la dirección del aumento de conocimiento, si es que lo hay, en una forma como "Jesús (S) es Dios (P)." Y. más aún, podemos decir que el núcleo del desarrollo dogmático de Nicea a Calcedonia está dirigido a resolver precisamente esta cuestión.

La respuesta trillada es que, sabiendo ya, por una "teologia natural," es decir, por un raciocinio metafisico, lo que contiene la categoria Dios, nos preguntamos si Jesús tiene derecho a entrar dentro de esa categoria. Pero la respuesta de Calcedonia es la opuesta. Si sólo podemos saber lo que es Dios por la 
historia de un Dios vivo, la categoría Dios está vacía hasta que la llenamos con el único caso en que Dios viviente nos hace asistir a su propia "historia."6

Como veiamos al analizar el desarrollo del dogma cristológico en los concilios que van desde Nicea hasta Calcedonia, el sujeto de la frase "Jesús es Dios" nos muestra, como contenido (como objeto material), una libertad que elige ser esto y no lo otro, que impone cierto valor - o deber-ser - a la totalidad del ser. En esıa elección aparece lo que es propio del mundo de la persona y de la libertad: al fijar un sentido a la existencia. A ese sentido elegido para su existencia, Jesús le dio un nombre -el "reino de Dios"- y asi ese sentido esıructuró su vida entera. Pues bien, decir que Dios es amor, decir que Dios es lo que el reino quiere ser, todas son expresiones de lo que la historia de Jesús puso de manifiesto y con lo único que podemos llenar el concepto no del todo 〔elizmente llamado "naturaleza divina." En el cómo vivió Jesús su vida humana está su divinidad; no "fuera" ni "mezclada" con aquéllo.

2. Pero si nos detuvièramos aqui, resultaria que la frase "Jesús es Dios" equivaldria meramente a la frase tautológica "Jesús es Jesús." En otras palabras, el conocimiento no iria de $S$ a $P$, porque $P$ diria exactamente lo mismo que $\mathrm{S}$. Por eso es precisamente aqui donde surge la necesidad de la segunda pregunta o cuestión: ¿están las dos frases - "Jesús es hombre" y "Jesús es Dios" - en el mismo plano lógico?

Veamos primero qué queremos decir con la pregunta, muy poco -demasiado poco- utilizada en teología. Como es evidente, la comunicación (de conocimientos) no se hace trasladando la cosa misma de que se trata, desde el transmisor al receptor. Lo que se Iransmite $-y$ vehícula un aporte cognoscitivo- es un mensaje en código. De ahi que se necesiten en toda comunicación dos operaciones: una, la de codificar una diferencia percibida; la olra, la de decodificar, o sea, interpretar lo que está en código, para lo cual es menester separar los elementos propios del código para quedarnos con el conocimiento de la diferencia percibida por el transmisor. Valga un ejemplo. Supongamos que una máquina percibe una di erencia de lemperatura (apreciable dentro de sus sensores). Para comunicar esa diferencia, no trasmite la "dilerencia de temperatura" misma, sino que primero la pone en código: v.gr. 30 grados. La persona o máquina que recibe ese mensaje no "recibe" la temperalura calurosa. Puede estar helado de frio y el mensaje no cambiará su temperalura. Pero para recibir la comunicación debe saber qué significa 30 grados. O sea, sacar el contenido de la comunicación de su código, para lo cual debe, primero, interprelarlo y luego desechar los elementos propios del código. En efecto, en lo que percibe si se mueve hasta donde estaba el receptor, no encontrará ningún “30." Esto pertenece al código utilizado para la comunicación, y no a la cosa comunicada.

Pues bien, los niveles lógicos corresponden a los diferentes niveles de absIracción de los códigos empleados para comunicar alguna diferencia percibida. Así, por ejemplo, el color verde de un determinado paisaje territorial del campo, y el color rojo con que ese mismo territorio esı́ codificado en un mapa, no se pueden "mezclar." El verde del paisaje campestre es ya, por cierto, un códi- 
go (el visual, transportado al lenguaje). Pero posee un "nivel" de abstracción inferior al del mapa. Por eso ese verde del paisaje se puede mezclar con el código de la temperatura o con el código de la altura sobre el mar. El mapa, empero, es más absıracto como código. Por eso se dice, en lógica, aunque la expresión no sea totalmente exacta, que "el mapa no es el territorio." Su verde no es señal de que el territorio sea verde. En el código que es el mapa, el verde es sólo una manera de hacer percibir mejor al que "decodifica" dónde se sitúan los limites de ese territorio y a partir de qué diferencia en la extensión del traslado se pasa a un territorio diferente (por ejemplo a otra nación).

Ahora bien, el concepto de "mapa" (como el de "grados de temperatura," "relieve orográfico," etc.) son conceptos formales en el sentido de que aluden a un vacio de contenido material. Designan un código de información, no al contenido de ésıa. El "verde" del mapa no designa un verde determinado en el territorio: es un instrumento para transmitir, en general, límites. Precisamente los mapas son, en general, explícitos acerca de su "formalidad:" añaden una escala, con lo cual indican a quien los ve cómo los debe interpretar $o$, lo que es lo mismo, cómo hacer para decodificarlos. Por ejemplo, dos centimetros en el mapa corresponden a dos kilómetros en el territorio.

No sé si el lector habrá estado percibiendo desde hace rato en este párrafo similitudes con elementos teológicos acerca de la divinidad de Jesús establecidos por los concilios cristológicos. Veamos un poco en qué consisten.

Cuando se dice que las características de la divinidad de Jesús no se pueden mezclar con las de su humanidad, se nos está diciendo algo paralelo al consejo lógico de no tomar el mapa por el rerritorio. En efecto, mezclar el verde del mapa con el color del territorio es una torpeza lógica, porque el mapa y el territorio están en dos niveles diferentes de abstracción.

Cuando se dice que no se pueden separar las caracteristicas percibidas en la historia de Jesús, de lo divino, se nos dice algo paralelo a cuando se advierte que no se puede "separar" el mapa del territorio, porque sólo el territorio concreto le da contenido "material" al mapa. De lo contrario, percibir un mapa imaginario me llevaria a la conclusión de que conozco un nuevo territorio.

Cuando se dice que en la divinidad de Jesús no hay ouro contenido que lo que se percibe en su humanidad, no se está diciendo que haya que negar el contenido "formal" de divinidad y su decisiva importancia. Es algo paralelo a la escala en la que se nos dice qué método usar para averiguar (en el grado de abstracción propio del mapa) la extensión del territorio, que yo podria averiguar por el código más concreto de recorrerlo a pie.

"Jesús es Dios" cumple en el lenguaje una función paralela a la de un mapa. Es la escala en que se cumple lo que Jesús decidió ser y realizar. Es la escala que me dice en qué medida la realidad se pliega a ese reino de Dios que Jesús buscó concreta y limiladamente. Y que, según todas las apariencias, terıninó en un fracaso. "Jesús es Dios" significa así que la libertad limitada de Jesús hombre está, en el ser sin limites de Dios, elevada a una potencia infinita de realización. En efecto, la "formalidad" del concepto que Jesús viene a llenar 
con su historia humana es la infinitud propia de Dios. Pero no es ninguno de esos presunios resulfados lógicos que el hombre pensó sacar convirtiendo directamente (como si se hiciera de un mapa un territorio) la infinitud formal en existencia concreta.

Así mantiene a rajatabla Calcedonia la plena razón de la teologia joánica cuando ésta pone en labios de Jesús, la queja: "Tanto tiempo hace que estoy con ustedes, $i y$ no me conoces, Felipe? Quien me ha visto a mi ha visto al Padre (=al Dios). ¿Cómo dices tú: “Muéstranos al Padre'?” (Jn. 14,9). En efecto, siguiendo el hilo que hemos remontado a través de los primeros concilios ecuménicos, se comprende el porqué nada hay en la esencia del Padre, en el ser que "el Dios" eligió libremente ser, que no esté visible en la "historia" de la libertad de Jesús, "el Hijo de Dios." Nada "nuevo" se conseguiría con ver al Padre, como dice el "teólogo" que, según Juan, habla por boca de Jesús. Es cierto que el Padre es lo que vemos en Jesús, pero en otra dimensión que se nos escapa. Pero el pedido de Felipe seria desatinado si fuera el de captar, desde el hombre, la infinitud con que el Padre posee lo que se torna visible en la vida cabalmente humana de Jesús. El hombre no podría "ver" eso que se le mostraria.

\section{$\mathbf{V}$}

Creo que con esta última frase del párrafo anterior, y después de tan largo periplo, estoy otra vez en el comienzo, respondiendo al deseo de Javier Jiménez Limón: que me explicara "más" sobre el misterio absoluto de Dios. Después de lo dicho hasta aqui, creo que ese "más" puede y debe ser muy breve: sólo unas breves sugerencias que quien haya leido y aceptado lo anterior podrá hacer y extender por cuenta propia.

La unión de esos dos términos - "misterio" y "absoluto" - requiere unas breves puntualizaciones para no caer en una mera lucha de palabras. Y comencemos por el primero. "Misterio" tiene en teologia un sentido específico que lo asimila a otro término, aún más vasto: "sobrenatural." Así como nadie puede exigir lo que es esencialmente gratuito y sobrepasa sus derechos y capacidad (nalurales), así ocurre, en el plano del conocer, con el misterio. Podriamos decir que éste es el equivalente cognoscitivo del ićrmino "gracia de Dios" o "sobrenatural."

De ahi lo que técnicamente constituye un misterio en teologia: "aparte aquellas cosas que la razón nalural puede alcanzar, se nos proponen para creer misterios escondidos en Dios de los que, a no haber sido divinamente revelados, no se pudiera tener nolicia" (Denz. 1795). Ahora bien, la revelación es ya un hecho. La "historia de la libertad divina," que sólo Dios nos podia abrir (porque conocer su "naturaleza infinita" por la razón no nos ayudaba para saber nada de lo que Dios habia decidido ser, se nos manilestó de mil maneras, primero desde lejos, por asi decirlo, en el Antiguo Testamento y luego, de una manera personal, en el Hijo o Verbo de Dios (Heb. 1, 1-2). A partir de ahi, ya habría que hablar de misterio en pasado, puesto que, de acuerdo a la misma carta a los Hebreos y a muchos otros lugares del Nuevo Testamento, la obscu- 
ridad que envolvía a Dios se vuelve "palabra dicha," "discernimiento," "gloria," o sea, luz.

En el siglo XIX - tal vez para salvaguardar lo religioso contra las pretensiones excluyentes de la ciencia (positivista) - se insiste en asociar el misterio, aun revelado, con obscuridad. Seria algo tan por encima de nuestra capacidad, que, aún después de saberlo, tenemos que renunciar a comprenderlo. Recuerdo la anécdota con que se desacreditaba a un profesor de teologia diciendo que, después de sus explicaciones tan completas del misterio trinitario, ya no quedaba en él nada de "misterioso"... En realidad, las fórmulas dogmáticas más relevantes de ese periodo, al respecio de los misterios, son mucho más equilibradas. Ponen mayor énfasis en la luz que ha llegado, y menos en las tinieblas que todavia permanecen. Para citar, una vez más, al Vaticano I, éste escribe: "los misterios divinos, por su propia naturaleza, de tal manera sobrepasan el entendimiento creado que, aun enseñados por la revelación y aceptados por la fe, siguen, no obstante, encubiertos por el velo de la misma fe y envueltos de cierıa obscuridad"' (Denz. 1796. Subrayado nuestro. El mismo párrafo habla de que se "alcanza alguna inteligencia, y muy fructuosa, de los misterios" cuando "la razón es ilustrada por la fe").

El aspecto "luminoso" de los misterios divinos una vez revelados, es, como se vio al comienzo de este artículo, acentuado por el Vaticano ll, cuando se dice que la revelación del misterio del Padre y de su amor es asimismo la revelación del misterio del hombre y de su destino, y que asi la fe todo lo ilumina con nueva luz, luz con la cual los problemas que el hombre enfrenta pueden ser solucionados de una manera más humana (Cr. GS 22,11 y passim).

¿A qué se refiere entonces el misterio cuando se lo declara "absoluto"? Obviamente a Dios. El sentido de la expresión -con cierto dejo decimonónico - no es tanto el de luz absoluta cuanto el de obscuridad absoluta. Aunque no pretenda indicar una obscuridad "total," alude a un limite más allá del cual el hombre tiene que rendirse. $O$, si no el hombre, ciertas facultades de éste, como la razón. El mismo Vaticano I alude a tal límite al hablar del "entendimiento creado." Por lo tanto es lógico suponer que la obscuridad comienza cuando ese entendimiento o razón quiere franquear el limite entre la realidad finita y la infinita. Y que ello ocurre aún después que el Hijo le cuenta al hombre el ser más intimo - "el seno"- del Padre (Jn. I,18).

Con todo esto in mente, y volviendo a la significación de Calcedonia desarrollada en lo que precede, ia qué conclusiones podemos llegar acerca del "misterio absoluto"?

La primera es, a mi parecer, que, debido a su dependencia - y a la dependencia posterior de toda la teologia cristiana- de la filosofia griega, Calcedonia no tuvo el tremendo impacto liberador que debia haber producido. La teologia de los siglos siguientes, con su pastoral implicita, siguió acomodando la historia de Jesús a su concepción de Dios, y no su concepción de Dios a la historia de Jesús. Lo infinito siguió siendo procurado directamente como un conocimiento surgido por deducción a partir del concepto de naturaleza divina. El resultado inmediato de esto fue la sensible pérdida de mordiente terre- 
na, digámoslo asi, de Jesús. No sólo, o no tanto, en cuanto hombre, sino encuanıo Dios. La parcialidad hisıórica de Jesús dejaba asi de formar parte del "misterio absoluto." Habia que prescindir de aquélla para penetrar, de alguna manera y en cierta medida, en la "Irascendencia divina."

La segunda consecuencia, procedente de la anterior, es la victoriosa sublevación de la idolatría conıra el mensaje cristiano sobre Dios. "No hay núcleo -escribe Henri de Lubac - en torno al cual se aglutine tanta hipocresia como la idea de Dios... El hombre tiene, sobre todo, desgraciadamente, miedo de Dios. Teme quemarse a su contacto, como los antiguos israelitas al tocar el arca. De ahi tantas sutilezas para negarlo, tanta maña para olvidarlo o tantas invenciones piadosas para amoriguar su choque... Incredulos, indiferentes, creyentes, todos rivalizamos en ingenio para protegernos de Dios." 7 Yo añadiria que no se necesita sospechar demasiado para añadir que todos rivalizamos en ingenio para protegernos, con (un falso) Dios, de los demás. O sea de un Dios que nos espera en cada hombre no-hombre que espera nuesiro amor. ¿Cómo se ha vuelto posible esta idolatria? En gran parte porque se perdió el freno colocado por Calcedonia. La vacuidad del "misterio absoluto" se presta para que el hombre coloque alli, sin tener que disfrazarlos demasiado, sus intereses humanos. Y cuando se pregunta cómo es posible que Dios y sus "valores" parezcan tan distintos del Jesús que recorrió nuestra historia, la respuesta es siempre el "misterio:" todo cambia cuando atravesamos la linea entre lo finito y lo infinito... La contemplación -mistica- del misterio absoluto, en cuanto no es contemplación en la acción, se ha convertido en una leología paralela donde se avanza tanto hacia el interior de Dios cuanto más se agosta la sensibilidad del hombre a lo que ocurre en torno a sí y en los demás.

En tercer lugar, y en contraposición a lo dicho, la contemplación de Dios, de sus valores y de sus planes a través de la historia terrena y conflictiva de Jesús, arroja luz, no obscuridad, sobre la construcción de una historia donde se levanta ya desde ahora (aunque sólo se manifieste en la meta-historia) la nueva tierra de los hombres y el nuevo cielo de Dios (GS 39). Es obvio que nuestro acceso a Dios se hace asi en y a través de la historia y que la luz que brota del "misterio absoluto" "no amortigua sino aviva la preocupación de perfeccionar esta tierra" (ib.). Aquí se juega toda la teologia de la liberación.

Finalmente, y en cuarto lugar, esta concepción del "misterio absoluto" como luz, y no como obscuridad, no deja de admitir que, en el paso de una formalidad a otra, de la humana a la divina, existe una obscuridad que no es otra que nuestra incapacidad para darle cualquier contenido concreto a lo infinito. Pero creo que esta formalidad, como formalidad que es, no puede ser objeto de contemplación. Esta formalidad no es Dios, a secas. Dios es lo que se contiene en ella, que es lo que se contiene en la vida visible, amable y comprensible de Jesús de Nazaret. Cómo los valores de Jesús puedan ser cuando no lengan los límites de nuestra hisıoria no puede ser objeto de contemplación. lnútil sería querer imaginarlo, sentirlo, vivirlo, a no ser como confirmación absoluta de lo que vivimos y sentimos en lo limitado. No podemos saber cómo será la nueva tierra una vez despojada de su limitación, porque esa limitación es lo que nos la hace accesible y querida: "no queremos, dice Pablo, que nos 
saquen esta carpa en que vivimos, sino que se le inyecte vida a lo que se nos corrompe entre las manos" ( 2 Cor. 5,4$)$. El "misterio absoluto" no es lo absoluto de una tiniebla impenetrable, sino lo absoluto de una luz que "lo ilumina lodo."

\section{NOTAS}

I. Sobre la "Cristologia" de Juan Luis Segundo, Christus, 1984, 577, pp. 57-61.

2. Ediciones Cristiandad. Madrid, 1982. L.a critica, tan disiretia que es mas bien tha pregunta, se refiere probablemente al tomo II/2 de la obra, que llesa como ritulo general "Las cristologias en la espiritualidad." Me atreveria a decir que hace referencia mas en particular aun, al capitulo I de la parte III: "Jesús y Dios: aproxiınacion al concilio de Calcedonia." En todo caso, este capilulo, que aqui comentamos y, hasta cierıo punto. reformulamos, deberá ser decisivo para ensayar una respuesıa a su planiearnienıo.

3. Parece ser de mal gusto poner cuadros en un trabajo teológico. Me resigno, sin embargo, a incurrir en esa falta para hacer un poco más claro, hasıa de un modo visual, el desarrollo que el planteamiento cristológico tiene desde el primer concilio ccuménico (Nicea) hasta el cuarıo (Calcedonia). Como el texto mismo del articulo lo sertala, tiene en ese cuadro importancia simbólica la linea que, dentro del cuadro, separa (léase, ell código: distingue) lo que luego se denominará la "naturalezs" divina y la "naluraleza" humana. Por regla general, lo que coloco entre paréntesis sirve para indicar una versión algo más moderna de lo que dice expresamente el concilio en cuestión. Asi, por ejemplo, el tèrmino "historia" no se hallará como tal en Nicea, pero sí descubrirá la lectura que lo que se predica del hombre Jesús son los acontecimientos hisióricos más relevantes de su vida. Lo que no esıá entre paréntesis son los términos usados explicitamente por los concilios. Asi, por ejemplo, mientras Efeso se limita a decir que no hay que hablar de "dos personas o hipostasis," en Calcedonia ya se expresa en forma positiva: "una persona o hipostasis." "Siguiendo esta linea de conducta cabria, en el tercer cuadro, poner entre partntesis "comunicación de lenguajes dejando luera del paréntesis sin confusión,expresión que se halla explícita en Calcedonia.

4. Lo que sigue en este párrafo debe mucho a una profunda observación de Nicolás Berdiaeff, según la cual términos o conceptos claves de la filosofla han sido, en realidad, elaborados en controversias históricas de la teologia. Tal el concepto de persona, que debe su entrada en la fílosofia y su estatuto central en ella hoy en dia a la problemética de la trinidad y de la cristologla cristianas. Indico, ya desde aqul, que una consecuencia de esto toca de lleno la problemática planteada por Jimenez Limón. El "misterio" de Dios no se halla, por lo menos en su ralz, en la infínitud del ser divino. El misterio de Dios es, en su esencia, el misterio de toda libertad: soblo la autorrevelación de esa libertad como historia, ese comienzo del amor que consiste en darse "a conocer," abre el verdadero camino hacia lo que es personal. Toda persona, aun la humana, contiene ese "misterio," ese "yo soy el que soy." El que la naturaleza divina sea infinita coloce un limite infranqueable a nuestra curiosidad, pero no impide la autodoneción (aun cognoscitiva, siempre amorosa) de Dios (Cr. Juan Luis Segundo, Berdiaeff. Une reflexion chrêtienne sur la personne. Paris: Aubier, 1963, especialmente Parte I, cap. III y par(e II, cap. IV).

5. Es importante sehalar en este texı que el criterio de la "cercania" de Dios, vélido tanto para los judlos como para los oiros pueblos (paganos), no es el que Dios se revele con más "claridad" intelectual a Israel: es que, a raiz de esa "revelación." aumenta la sabiduria, la inteligencia y la justicia humanas de ese pueblo. De aquello otro no habrlan podido ser jueces los que aún no conocian a Yahve.

6. Uno de los puntos centrales de la teologia de la liberación se halla, a mi modo de ver, aquí. $Y$, consiguientemente, uno de los puntos en que me parece más dudosa la teologla que usa la Insirucción de la comision para la doctrina de la fe sobre "ciertos aspectos" de aquélla es el rehusarse a efirmar que "Dlos se hace historia" (Insinuccion sobre algunos "aspectos de la Teología de la Liberación. "Rome, 1984, 1X, 3). ¿Será, entonces, incorrecto decir que el Verbo se hizo carne? ¿No signlfica "carne" en el lenguaje blblico, existencia creatural, contingente, hlstórica, una "carpa" de nómada que el Verbo, según el prólogo de Juan, instala entre las nuestras? ¿Hasta dónde se respetan aqul Efeso y Calcedonia?

7. Henri de Lubac (Cardenal), Por los caminas de Dios. Trad. cast. Buenos Aires: Ed. Carlos Lohle, 1962, 127 y 133. 